\title{
ESTUDO SOBRE MODELOS DE GOVERNANÇA EM ZONAS PORTUÁRIAS E INDUSTRIAIS: O CASO DO PECÉM E DE MARSELHA-FOS
}

\author{
RESEARCH ABOUT GOVERNANCE MODELS IN INDUSTRIAL \\ PORT ZONES: THE CASE OF PECÉM AND MARSEILLES-FOS
}

\author{
ESTUDIO SOBRE MODELOS DE GOBERNANZA EN ZONAS \\ PORTUARIAS E INDUSTRIALES: EL CASO DE PECÉM Y DE \\ MARSELLA-FOS
}

\author{
Denio Igor Silva Pontes \\ Professor de Economia e Logística da Faculdade CDL \\ (Câmara de Dirigentes Lojistas), Brasil / Pesquisador \\ associado ao Laboratório Cret-Log, Aix-Marseille \\ Université, França / Doutorando e mestre em Gestão, \\ estratégia e logística pela Université Aix-Marseille, \\ França / Mestre em Economia do Setor Público pela \\ Universidade Federal do Ceará, Brasil. \\ igorpontesce@hotmail.com
}

\author{
Contextus \\ ISSNe 2178-9258 \\ Organização: Comitê Científico Interinstitucional \\ Editor Científico: Carlos Adriano Santos Gomes \\ Avaliação: double blind review pelo SEER/OJS \\ Edição de texto e de layout: Carlos Daniel Andrade \\ Recebido em 17/03/2017 \\ Aceito em 11/09/2017 \\ $2^{a}$ versão aceita em 04/10/2017
}

\section{RESUMO}

Neste artigo, será abordada a governança de zonas industriais e portuárias (ZIP), tema que perpassa a questão da gestão portuária stricto sensu, mas tem escopo mais abrangente ao relacionar-se com o problema da gestão de áreas que congregam todo um conjunto de ativos físicos e atores: infraestruturas logísticas em sua multimodalidade, centros de distribuição, zonas industriais, prestadores de serviços, autoridade portuária e empresas. Ao longo desta pesquisa, buscou-se compreender e descrever o modelo de governança portuária de duas ZIPs: uma situada no Brasil, no estado do Ceará, e a outra, no mar Mediterrâneo, na França. Para isso, foram realizadas pesquisas de campo nas duas regiões. O porto de Roterdã foi utilizado como modelo de parametrização para as duas ZIPs estudadas. Identificou-se que, para uma ZIP obter êxito, seu modelo de governança deve tratar de modo indissociável os setores logísticos e industriais, de preferência com foco na região onde está inserida, ao executar a gestão e buscar o desenvolvimento econômico e social.

Palavras-chave: Governança de zonas industriais e portuárias. Gestão portuária. Infraestrutura logística.

\begin{abstract}
This article will address governance of industrial port zones (IPZ), a topic that pervades the issue of port management stricto sensu but has a broader scope insofar as it relates to the problem of managing areas that congregate a whole set of physical assets and actors: logistic infrastructures in their multimodality, distribution centers, industrial zones, service providers, port authorities and companies. Throughout this research, we sought to understand and describe the port governance model of two IPZs - the one located in the Brazilian state of Ceará and the other in the Mediterranean Sea, in France. For this, field researches were carried out in both regions. The port of Rotterdam was used as a parameterization model for the two IPZs studied. It was identified that, for an IPZ to be successful, its governance model must assume logistics and industrial sectors as mutually inseparable, preferably with a focus on the region where it is inserted, both when executing management and when seeking economic, social development.
\end{abstract}

Key-words: Governance of industrial port zones. Port management. Logistical infrastructure.

\section{RESUMEN}

En este artículo, se abordará la gobernanza de zonas industriales y portuarias (ZIP), tema que atraviesa la cuestión de la gestión portuaria stricto sensu, pero tiene alcance más amplio al relacionarse con el problema de la gestión de áreas que congregan todo un conjunto de activos físicos y actores: infraestructuras logísticas en su 
multimodalidad, centros de distribución, zonas industriales, prestadores de servicios, autoridad portuaria y empresas. A lo largo de esta investigación, se buscó comprender y describir el modelo de gobernanza portuaria de dos ZIPs: una situada en Brasil, en el estado de Ceará, y la otra, en el mar Mediterráneo, en Francia. Para ello, se realizaron investigaciones de campo en las dos regiones. El puerto de Rotterdam fue utilizado como modelo de parametrización para los dos ZIPs estudiados. Se identificó que, para un ZIP obtener éxito, su modelo de gobernanza debe tratar de modo indisociable los sectores logísticos e industriales, de preferencia con foco en la región donde está inserta, al ejecutar la gestión y buscar el desarrollo económico y social.

Palabras clave: Gobernanza de zonas industriales y portuarias. Gestión portuaria. Infraestructura logística.

\section{INTRODUÇÃO}

Com o advento da globalização, os portos tornaram-se elementos-chave para o desenvolvimento do comércio internacional. Grandes unidades de produção industrial estão concentradas próximas a eles, os quais funcionam como centros de gravidade de atividades econômicas, ao permitirem otimizar custos logísticos e aumentar a competitividade (FALCÃO; CORREIA, 2012). Uma zona industrial e portuária (ZIP), espaço que associa atividades industriais e portuárias, congrega uma grande quantidade de atores em um intrincado conjunto de interrelações. Tudo isso em conexão com infraestruturas de transporte terrestre responsáveis por conectar a ZIP com sua hinterlândia e, assim, ampliar sua área de influência no continente. A ZIP é também um conjunto de atividades e serviços ofertados a cada navio e a cada mercadoria por uma variedade de prestadores de serviços e órgãos anuentes (HALLOUËTGUEGUEN, 2014).
Foi no Japão que se desenvolveram as primeiras ZIPs, chamadas de MIDA (maritime industrial development areas), em 1950. Na França, as primeiras plataformas industriais portuárias surgiram na década de 1960. Assim, nasce a ZIP de Fos, em 1962, no mar Mediterrâneo (GUILLAUME, 2014), a qual figura entre as três grandes ZIPs da França, respectivamente: Haropa (Le Havre, Rouen e Paris), Marselha Fos e Dunkerque. Contudo, a obsoleta regulamentação dos portos franceses, vigorante e imutável desde 1947, impediu a atualização do sistema. A solução prática e objetiva encontrada pelos empresários franceses foi a utilização crescente dos eficientes portos belgas e holandeses. Com isso, o porto belga de Antuérpia tornou-se o primeiro porto importador francês e o principal ponto de entrada de mercadorias com destinação a Paris (CATOIRE, 2013).

A reestruturação do sistema portuário francês só ocorreu em 9 de junho de 1992, com a Lei n 92-496. Esta, por sua vez, foi modernizada com a reforma de 4 de julho de 2008 (Lei n 2008-860), que teve 
por objetivo transferir a superestrutura e os trabalhadores para operadores privados, bem como criar para a governança portuária conselhos de administração e de desenvolvimento. Uma terceira lei, batizada de "economia azul", de 20 de junho de 2016, tratou, dentre outras medidas, de criar em cada grande porto francês um conselho encarregado de coordenar os investimentos privados e públicos.

No Brasil, a região Nordeste destaca-se pela tradição no desenvolvimento de complexos industriais e portuários. Dentre eles, podemos citar as infraestruturas dos estados de Bahia, Pernambuco e Ceará. Inaugurado em 1975, o Porto de Aratu, na Bahia, viabilizou as operações dos dois principais polos industriais do estado: o Centro Industrial de Aratu (CIA) e o Polo Industrial de Camaçari (o primeiro complexo planejado do país). Quanto a Pernambuco, o Complexo Industrial Portuário de Suape completou 38 anos em 2016. Em 2002, foi a vez de o Complexo Industrial e Portuário do Pecém ser inaugurado, no Estado do Ceará.

O setor portuário nacional começou a passar por modernizações a partir da década de 1990, com esforços para torná-lo mais eficiente, como a ampliação de investimentos e a promoção da participação privada (BRITTO et al., 2015). Dessa forma, em 1993, a Lei nº 8.630/1993 (“Lei dos Portos") reduziu o papel do Estado como gestor e operador portuário e permitiu a entrada de agentes privados. Em 2013, uma nova norma, a Lei $n^{\circ} 12.815 / 2013$, eliminou as restrições ainda existentes à constituição de terminais de uso privativo (TUP), os quais deixaram de ter a obrigatoriedade de movimentar somente carga própria. As reformas no setor indicam uma tendência de maior participação privada, com impactos significativos sobre a concorrência e ganhos de eficiência. $\mathrm{O}$ objetivo era combater certa inércia das companhias docas, que - de acordo com dados da Confederação Nacional das Indústrias (2016) - investiu, de 2000 a 2016, apenas $29,5 \%$ dos R $\$ 14,6$ bilhões de que dispunham em seus orçamentos.

Configura-se como objetivo da presente pesquisa compreender os mecanismos subjacentes à governança portuária e territorial de uma ZIP com base no caso de dois complexos industriais e portuários, situados no Brasil e na França. São dois países que possuem em comum, além de fragilidades específicas da gestão portuária, debilidades institucionais e organizacionais no que se refere à gestão de área da ZIP. Ademais, compreende-se como lacuna da literatura acadêmica a insuficiência de tipologias e modelos de governança para ZIPs, em contraste com os modelos portuários sugeridos pelo Port 
Reform Toolkit, produzido pelo Banco Mundial (2003).

Nesse contexto, identificamos que, tanto no Brasil como na França, ainda não há consenso em torno dos modelos de governança de ZIPs; pelo contrário, eles são visivelmente frágeis e carentes de coesão, contrapondo-se sobremaneira aos praticados nas ZIPs do Norte da Europa como, por exemplo, o porto de Roterdã, que utilizaremos ao longo da pesquisa como um caso paramétrico. Uma ZIP requer modelos de governanças capazes de atender as demandas dos atores envolvidos com foco: na qualidade e eficiência dos serviços prestados; na ampliação da sua área de influência, seja atraindo novas rotas marítimas, seja ampliando as conexões com a hinterlândia; no estímulo à transição do setor industrial para novas matrizes energéticas; na pilotagem dos stakeholders geograficamente próximos para promover inovação colaborativa.

Assim, ensejamos ao longo desta pesquisa descrever o estado da arte não apenas das tipologias e características dos portos, mas também dos modelos de governança portuária. Também visamos produzir uma análise descritiva e comparativa dos modelos adotados pelos portos do Pecém, no Brasil, e de Marselha, na França. Com base nisso, proporemos diretrizes a serem incorporadas ao business model das autoridades portuárias.

Além desta introdução, o artigo está estruturado em quatro seções. Na segunda, mobilizaremos a literatura fonte da nossa fundamentação teórica: ZIPs, gestão portuária e gestão de uma ZIP (porto de Roterdã). Na terceira, apresentaremos as ZIPs selecionadas para nosso estudo de caso. $\mathrm{Na}$ quarta, descreveremos a metodologia utilizada na pesquisa. $\mathrm{Na}$ quinta, faremos uma análise dos resultados emergidos da confrontação entre o teórico e o empírico. E, na última seção, são agrupadas as principais conclusões.

\section{FUNDAMENTAÇÃO TEÓRICA}

\subsection{Zona industrial e portuária (ZIP)}

Pode-se definir a infraestrutura portuária como um local onde se processa a transferência de cargas e/ou passageiros entre vias navegáveis e terrestres (WORLD BANK, 2003; 2004), constituindo um nó intermodal na rede de transportes. Associadas a essa infraestrutura logística, são comumente instaladas grandes unidades de produção industrial visando otimizar os custos logísticos de distribuição e abastecimento (FALCÃO; CORREIA, 2012). De acordo com Guillaume (2014), reflete-se nas ZIPs a ideia clássica de 
indústria-chave, desenvolvida com base no conceito de polo de crescimento, o qual permite uma polarização de atividades produtivas. Para Perroux (1991), a polarização se opera pela concentração dos meios de produção no espaço, constituindo uma região de crescimento econômico capaz de produzir externalidades positivas que, por sua vez, favorecem o aparecimento de economias externas, advindas da proximidade dos atores produtivos às infraestruturas necessárias. Essas dotações infraestruturais acabam por produzir vantagens concorrenciais.

A ideia de criar uma ZIP torna-se mais evidente em um contexto de globalização e de "maritimização" da indústria pesada (siderúrgica e petroquímica). Assim, as políticas de industrialização e de exportação exercem papel preponderante na implantação dessas zonas ao redor do mundo (GUILLAUME, 2014). Nos trinta anos que sucedem a segunda guerra mundial, período conhecido como Les Trente Glorieuses, os portos se tornam regiões estratégicas para a indústria pesada. A nova indústria portuária desenvolve-se pela transformação de matérias-primas, e as ZIPs são logística e economicamente mais viáveis para gerir os grandes fluxos e operar a transformação industrial. Com isso, a proximidade das áreas de descarregamento de insumos e de carregamento de produtos manufaturados oferece a possibilidade de ser mais competitivo.

Uma ZIP consiste em um espaço que associa atividades portuárias e industriais em um sistema econômico e espacial complexo, podendo estar localizada no litoral ou às margens de um rio. De acordo com Guéguen-Hallouët (2014), uma ZIP é, ao mesmo tempo, uma entidade gestora e um espaço equipado e planejado de indústrias e infraestruturas. Estas últimas incluem instalações portuárias propriamente ditas - como ancoradouros, docas, cais, edificações e vias de circulação interna, dentre outras - e equipamentos de proteção e acesso aquaviário: quebramares, canais, bacias de evolução e áreas de fundeio, dentre outros. Tudo isso está conectado a infraestruturas de transporte (rodovias, ferrovias, gasodutos, oleodutos, canais navegáveis), de modo a oferecer a multimodalidade.

Também faz parte da ZIP o conjunto de atividades e serviços prestados a cada navio e a cada mercadoria por uma infinidade de prestadores: pilotos, companhias de rebocadores, agentes marítimos, armazéns, seguradoras, operadores logísticos, comissários de transporte, instituições intervenientes, agentes de carga, consignatários, transportadores rodoviários, ferroviários, 
fluviais etc. Na área da ZIP, há ainda terminais especializados a serviço: da indústria portuária, do transbordo de mercadorias e da oferta de serviços à hinterlândia próxima.

É do conjunto das indústrias e serviços - localizados quer na aglomeração da ZIP, quer em seus arredores - que parte o tráfego gerador: de renda para a autoridade portuária, de valor adicionado à mercadoria e de empregos para o território (TOURRET, 2011). Os portos de última geração desenvolveram um papel de interface das relações comerciais, mas, principalmente, de funções logísticas, como estocagem e distribuição de cargas líquidas, sólidas e diversas. O sucesso dos portos do Benelux (Bélgica, Países Baixos e Luxemburgo) está amparado na especialização desse tráfego industrial (TOURRET, 2011).

A massificação dos processos produtivos e das operações logísticas de distribuição imprimiram a necessidade de amplas reservas fundiárias e calados profundos. Dessa forma, nas primeiras décadas do século $\mathrm{XX}$, o volume de operações em torno da indústria alimentou um forte consumo de espaço portuário. Para superar as limitações e gargalos físicooperacionais impostos pelos portos tradicionais, as zonas portuárias saíram do espaço urbano para instalar-se em regiões afastadas dos centros urbanos (MONIÉ; VASCONCELOS, 2012). Para Wang e Olivier (2003), a tendência da migração de terminais portuários para locais periféricos mais adequados está relacionada também à importância das múltiplas conexões intermodais desafogadas dos centros urbanos. Verifica-se tal fenômeno no porto de Marselha (localizado na place De la Joliette), conforme a Foto 1, e, mais recentemente, em Fortaleza, com o Porto Organizado do Mucuripe.

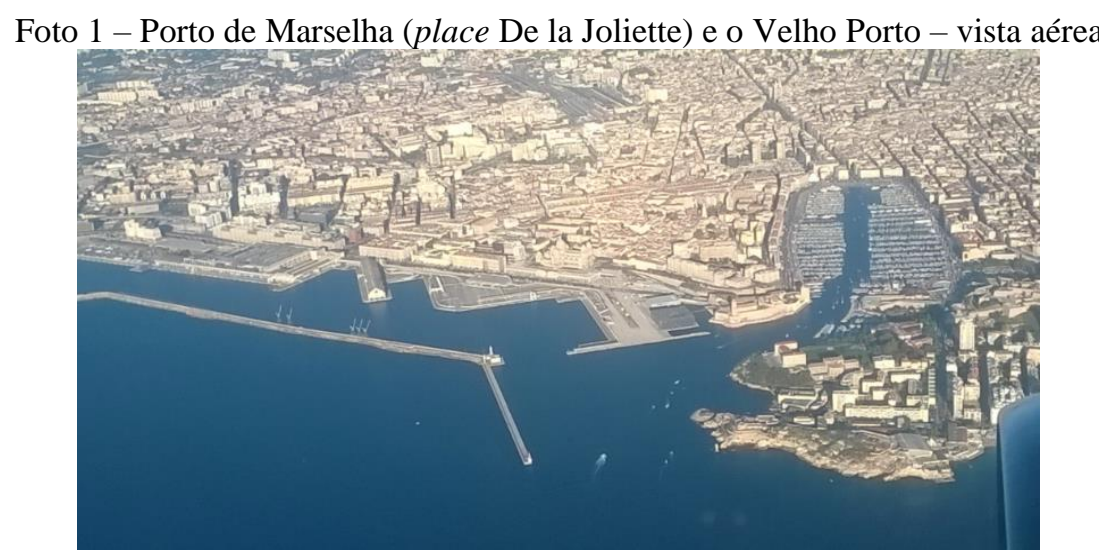

Fonte: foto do autor. 
A depender da disponibilidade de retroáreas, uma ZIP pode possuir duas fontes principais de receitas: o aluguel de espaços - como armazéns, terminais, câmaras frigoríficas, pátios de armazenagem - e o tráfego de navios, que requer esforços para atrair rotas de grandes armadores. Além disso, a área onde estão instaladas as indústrias também pode ser uma importante fonte de receita.

Em alguns portos do mundo, como os de Roterdã e Antuérpia, a fonte de receita oriunda da locação de espaços é tão importante quanto aquela obtida pelo tráfego de navios. Destacamos abaixo algumas possíveis configurações portuárias:

- porto de entrada regional (gateway): estrutura onde as cargas chegam e adentram ou saem do continente, repercutindo sobre a cadeia logística, seja de transporte ou de armazenamento, e sobre os diversos serviços que podem ser agregados à mercadoria importada ou exportada. Aqui, existe uma preocupação de expandir a sua área de influência (hinterlândia), como forma de atrair novos negócios;

- porto de transbordo (transshipment): também conhecido como hub port, é especializado nos serviços marítimos de transbordo de contêineres entre navios mãe (mother vessels) e navios alimentadores (feeder vessels). Envolve dois movimentos portuários: o contêiner chega a um navio, é descarregado e armazenado temporariamente e, então, parte em outro navio. Esse tipo de tráfego gera receita para o porto, mas não tem para a economia local nenhum desdobramento ou um muito pequeno;

- porto industrial: além de poder ser um porto comercial, é geralmente capaz de produzir grande impacto na região onde está inserido, uma vez que possui nas proximidades grandes plantas fabris que empregam grande contingente de pessoas e, consequentemente, produzem uma série de externalidades positivas (spill-overs) na cadeia produtiva onde estão inseridos. Essa estrutura também pode gerar tráfego para o porto, pois consome grandes quantidades de matéria-prima e pode exportar o produto acabado.

Devido à grande quantidade de atores envolvidos, da variada gama de instalações e de possíveis configurações, os portos e, mais amplamente, as ZIPs não constituem tecnologias de produção homogênea, tratando-se, portanto, de ativos logísticos complexos do ponto de vista da gestão (NOTTEBOOM, 2002). Dessa forma, uma ZIP pode congregar em seu 
território múltiplas e complexas configurações organizacionais.

\subsection{Gestão portuária}

Os modelos de exploração de portos existentes hoje no mundo resultaram não apenas de anos de evolução tecnológica e jurídica, mas também de formas alternativas de organização e de governança, bem como de diferentes níveis de envolvimento entre entes públicos e privados. De acordo com Coutinho et. al (2013), para melhor compreender os modelos de exploração portuária, faz-se necessário agrupar as atividades portuárias em quatro categorias:

- regulamentação e supervisão dos serviços realizados: envolve o conjunto de obrigações e responsabilidades desempenhadas por uma autoridade portuária, definidas em geral por resoluções e normas legais. Normalmente, esse elemento não é transferido a um ente privado, devido às suas características eminentemente públicas;

- gestão das áreas comuns: responsável pela infraestrutura e superestrutura de uso comum, incluindo meios aquaviários. Essa atividade é típica de um landowner, que detém o direito de transferência permanente ou temporária de suas propriedades via alienação, arrendamento ou concessão de lotes dentro da área do porto;

- gestão de áreas de uso restrito dentro do porto: relativa às áreas com utilização decidida de forma apartada das decisões acerca das estruturas de uso comum. Esse é o caso de áreas de uso específico, como os terminais portuários;

- operação portuária: diz respeito à transferência de bens e passageiros entre uma embarcação e o cais, bem como à movimentação no porto. A transferência desse elemento para agentes privados permite a introdução de concorrência intraportos.

Apresentada essa classificação das atividades portuárias, faz-se necessário definir os modelos de exploração de portos existentes no mundo, os quais se diferenciam pelas formas de governança, pública ou privada. O Quadro 1 apresenta cinco modelos portuários sugeridos pelo documento Port Reform Toolkit, do Banco Mundial (2003). 
Quadro 1 - Formas de organização dos portos

\begin{tabular}{|c|l|l|}
\hline Nome & \multicolumn{1}{|c|}{ Descrição } & \multicolumn{1}{|c|}{ Adotado } \\
\hline $\begin{array}{c}\text { Porto público } \\
\text { (service port) }\end{array}$ & $\begin{array}{l}\text { Não envolve participação privada. Todas as } \\
\text { categorias de atividades portuárias são de } \\
\text { responsabilidade do poder público. }\end{array}$ & $\begin{array}{l}\text { Portos brasileiros } \\
\text { pré-1993 }\end{array}$ \\
\hline $\begin{array}{c}\text { Porto quase-público } \\
\text { (tool port) }\end{array}$ & $\begin{array}{l}\text { Participação privada apenas na operação } \\
\text { portuária, em atividades típicas de terminal. As } \\
\text { áreas de uso restrito são geridas como se fossem } \\
\text { áreas de uso comum. }\end{array}$ & Porto do Pecém \\
\hline $\begin{array}{c}\text { Porto público- } \\
\text { privado }\end{array}$ & $\begin{array}{l}\text { O poder público comporta-se como um típico } \\
\text { gestor de condomínio. As áreas de uso restrito } \\
\text { são concedidas através de contratos. }\end{array}$ & $\begin{array}{l}\text { Roterdã, } \\
\text { Marselha-Fos, } \\
\text { Santos, Suape }\end{array}$ \\
\hline $\begin{array}{c}\text { Porto quase-privado público) } \\
\text { (landlord privado) }\end{array}$ & $\begin{array}{l}\text { Difere do modelo anterior em relação à natureza } \\
\text { jurídica do gestor das áreas comuns. O landlord } \\
\text { é um agente privado. À autoridade portuária } \\
\text { cabem apenas as atividades de regulamentação e } \\
\text { supervisão. }\end{array}$ & $\begin{array}{l}\text { México após } \\
\text { 1993 - 16 portos } \\
\text { S.A. }\end{array}$ \\
\hline $\begin{array}{c}\text { Porto privado } \\
\text { (private port) }\end{array}$ & $\begin{array}{l}\text { Todos os elementos são privados. Não há } \\
\text { presença do poder público nas decisões de } \\
\text { planejamento e operação do porto. }\end{array}$ & $\begin{array}{l}\text { Alguns portos do } \\
\text { Reino Unido e } \\
\text { terminais de uso } \\
\text { privado (TUPs) } \\
\text { no Brasil }\end{array}$ \\
\hline
\end{tabular}

Fonte: adaptado de Britto et al., 2015.

Com base nessas definições, os quatro tipos de atividades e os cinco podemos apresentar o Quadro 2, associando modelos portuários.

Quadro 2 - Modelos de exploração de portos

\begin{tabular}{|l|l|l|l|l|}
\hline Modelo portuário & $\begin{array}{c}\text { Regulamentação e } \\
\text { supervisão }\end{array}$ & $\begin{array}{c}\text { Gestão de áreas } \\
\text { comuns }\end{array}$ & $\begin{array}{c}\text { Gestão de áreas } \\
\text { de uso restrito }\end{array}$ & $\begin{array}{c}\text { Operação } \\
\text { portuária }\end{array}$ \\
\hline Público & Pública & Pública & Não há & Pública \\
\hline Quase-público & Pública & Pública & Não há & Privada \\
\hline Público-privado & Pública & Pública & Privada & Privada \\
\hline Quase-privado & Pública & Privada & Privada & Privada \\
\hline Privado & Privada & Privada & Privada & Privada \\
\hline
\end{tabular}

Fonte: Coutinho et. al, 2013.

Os portos mais influentes do mundo enquadram-se no modelo de gestão públicoprivado (landlord público), baseado em contratos de aluguel, arrendamento ou cessão temporária de uso. Alternativamente, a área de uso restrito pode ser de propriedade definitiva do usuário (COUTINHO et. al, 2013). Ao agente privado, cabe dispor de máquinas e equipamentos (guindastes, empilhadeiras e veículos de carga: os portêineres, reachstackers e harbour cranes) necessários à prestação de serviços logísticos (BRITTO et al., 2015). Assim surge a maioria dos terminais especializados por tipo de carga. Nesse modelo, a autoridade pública detém e administra a infraestrutura do porto, resguardando para si as funções de regulamentação e supervisão, bem como a de gestão das áreas comuns. Também cobra 
as taxas portuárias de empresas lá atuam (COUTINHO et. al, 2013). O modelo é o mais comum no mundo. São alguns exemplos os portos de Roterdã (Holanda), o de Buenos Aires (Argentina), o de Marselha-Fos (França), o de Cingapura e a maioria dos portos brasileiros, tais como, Santos, Rio de Janeiro, Suape, Rio Grande, Itajaí etc.

\subsection{Governança de zonas industriais e portuárias (porto de Roterdã)}

Quando ampliamos a área do porto incluindo aquela destinada ao setor industrial da ZIP, também expandimos a complexidade da atividade gestora. O Porto de Roterdã, assim como outros grandes do mundo, tem conseguido equalizar essa relação implantando um modelo de governança calibrado conforme as diretrizes estratégicas e os dinâmicos e mutáveis desafios do setor. Dessa forma, apresentamos o modelo de governança da ZIP de Roterdã, como caso paramétrico para a consecução dos objetivos desta pesquisa.

De propriedade do governo municipal de Roterdã (70\%) e do estado holandês (30\%), aquela ZIP é gerida, operada e desenvolvida pela autoridade portuária de Roterdã. Tal configuração mantém a ZIP como infraestrutura voltada eminentemente para o desenvolvimento regional do município onde está localizada. A autoridade portuária, responsável inclusive pela área industrial, tem como objetivo reforçar a posição competitiva do porto como polo logístico e complexo industrial de classe mundial. Possui um volume anual de negócios de cerca de 600 milhões de euros e conta com aproximadamente 1.100 funcionários. A ZIP se estende da cidade ao Mar do Norte e compreende cerca de 5.000 ha de área industrial, contando com cinco refinarias, nove usinas termoelétricas e um movimento anual de 34 mil navios. Ela oferece emprego direto a mais de 90 mil pessoas $(12 \%$ da força de trabalho regional) e é responsável por 3\% do PIB holandês (PORT OF ROTTERDAM, 2017).

Os portos holandeses são objeto de um consenso local e nacional. Enquanto base fundamental da competitividade do país, beneficiam-se de uma atenção especial do poder público. Dessa maneira, não existe oposição significativa ao desenvolvimento de suas atividades. As organizações ambientais e as associações de habitantes colaboram com as autoridades portuárias. De acordo com Catoire (2013), não é raro presenciar participações construtivas da parte de moradores em reuniões públicas de informação da autoridade portuária de Roterdã. A gestão do porto é indissociável do território regional em seu entorno. 
A autoridade portuária empreende um papel de coordenador entre os diferentes atores econômicos: operadores de terminais, armadores, transportadores etc. A política de construção e manutenção dos canais de comunicação da autoridade portuária de Roterdã é uma marca no seu modelo de gestão. Essa capacidade é mobilizada em todos os processos de concertação local (CATOIRE, 2013).

Ilustra essa inclinação ao diálogo e à comunicação com o seu entorno o projeto Maasvlakte II, que se destaca como boa prática de governança. Diante de exigências por um calado mais profundo, pelo setor de contêineres, e de maiores extensões territoriais, pelo setor petroquímico, foi construído um ancoradouro com cerca de 20 metros de profundidade, localizado diretamente sobre o mar (PORT OF ROTTERDAM, 2016). O porto como um todo duplicou sua capacidade no tratamento de contêineres, ampliando a área em 1.000 ha. Foram construídos 3,5 km de cais, 11 $\mathrm{km}$ de diques, $24 \mathrm{~km}$ de estradas, $14 \mathrm{~km}$ de ferrovias, 560 ha de bacia marítima e dois terminais de contêineres de grande porte: o APM Terminals e o Rotterdam World Gateway (CATOIRE, 2013). Foram cinco anos de planejamento e concertações objetivando mitigar os contenciosos causados pela degradação ambiental e poluição industrial, além de atender a regulamentação europeia Natura 2000. Assim, como medida compensatória, o projeto inicial foi deslocado um quilômetro para o norte resultando em um custo adicional de aproximadamente dois terços do valor total do projeto, estimado inicialmente em 1 bilhão de euros. $\mathrm{O}$ Maasvlakte II foi inaugurado em 2013, quase exatamente como concebido em 2006-2007 (custo estimado de 1,7 bilhão e efetivo de 1,55 bilhão de euros).

A experiência na construção, no desenvolvimento e na gestão portuária e de áreas industriais possibilitou a criação do departamento Port of Rotterdam International (PoRint), que visa criar oportunidades de negócios no exterior, com a participação acionária em projetos portuários. O PoRint oferece serviços de consultoria em gestão portuária e acordos de joint venture, em que a autoridade do porto participa e investe em ZIPs. A rede de parcerias do porto de Roterdã (World Port Network) é composta pelo porto de Sohar (Omã), pelo Porto Central (Brasil) - em que possui joint ventures - e pelos portos do Pecém (Brasil), Balikesir (Turquia), Mundra (Índia) e Jacarta (Indonésia), em que desenvolve projetos de consultorias (URIBE, 2016).

A ZIP de Sohar está localizada no Oriente Médio, em Omã. O porto Sohar e a zona franca, operacionais desde 2002, são 
administrados pela Sohar Industrial Port Company (SIPC), uma joint venture de 50\% de participação da autoridade portuária de Roterdã e 50\% do governo de Omã. O Porto Central, um projeto greenfield localizado no Estado do Espírito Santo, é uma joint venture entre a empresa brasileira TPK Logística e a autoridade portuária de Roterdã. A ZIP está sendo desenvolvida no modelo de condomínio portuário, no qual os empreendedores se responsabilizam pela infraestrutura portuária e as áreas para a implantação de indústrias e terminais são arrendadas.

\subsubsection{Estrutura organizacional da ZIP de Roterdã}

O porto de Roterdã tem uma estrutura organizacional com departamentos responsáveis pelo desenvolvimento e manutenção do porto em si e da área industrial. Os departamentos comerciais são responsáveis por: acompanhar as empresas que executam negócios no porto, prospectar novos clientes e ramificar as cadeias produtivas. Existem dois departamentos comerciais: o de Contêineres, Carga fracionada e Logística (Containers, Break bulk \& Logistics) e o de Indústria e Carga a granel (Process Industry \& Bulk Goods). Juntamente com o departamento Porto de
Roterdã Internacional (PoRint), estão vinculados ao presidente e diretor executivo (CEO). Também estão vinculados ao CEO os departamentos de recursos humanos, comunicações e assuntos externos, auditoria interna, jurídico e assuntos corporativos.

No porto de Roterdã, compete à autoridade portuária desenvolver e manter a área portuária e industrial. Essas responsabilidades recaem, mais especificamente, sobre os departamentos de desenvolvimento portuário, gestão de recursos, gestão ambiental e instalações, vinculados ao vice-presidente sênior e diretor de operações de infraestruturas e assuntos marítimos (COO).

O vice-presidente executivo e diretor financeiro e de gestão da informação (CFO) é responsável pelas finanças e financiamento, gestão da informação, gestão de riscos e (qualidade da) tomada de decisões sobre investimentos. O Harbour Master's Division (Capitania dos Portos) ocupa um lugar de destaque no organograma. É ele que realiza as funções públicas, tais como orientação de tráfego, inspeção e controle de incidentes, atribuídas a esse departamento pelo governo holandês e pelos municípios de Roterdã, Dordrecht, Schiedam e Vlaardingen. 
Figura 1 - Organograma do porto de Roterdã

Autoridade Portuária de Roterdã

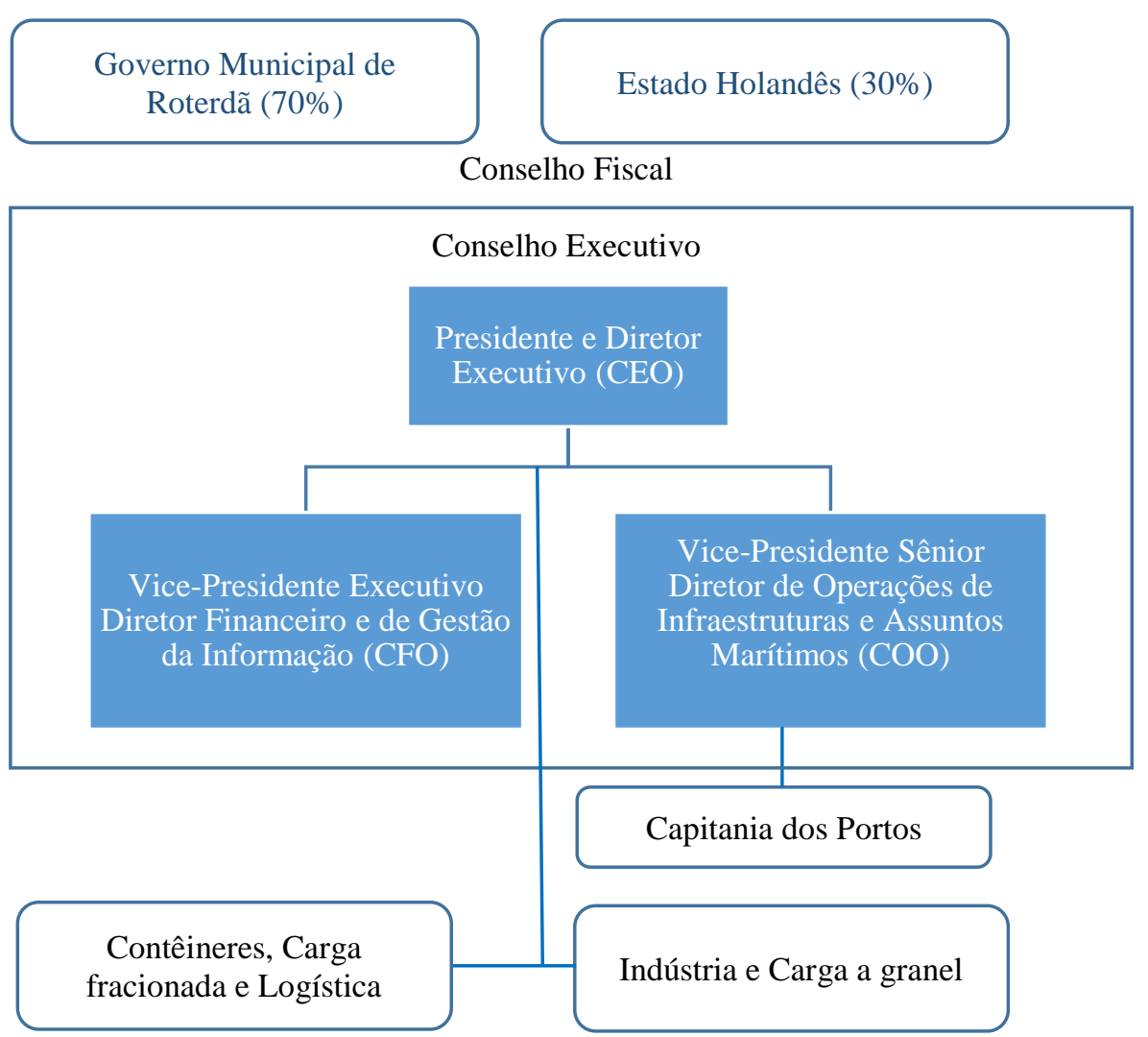

Fonte: adaptado do site do porto de Roterdã.

\section{ESTUDO DE CASO}

\subsection{Porto de Marselha-Fos}

A história do porto de Marselha remonta ao século VI a.C, na área hoje conhecida como Velho Porto (Vieux-Port). $\mathrm{O}$ atual porto de Marselha-Fos estende-se por uma distância de setenta quilômetros, de Marselha (passageiros e cargas) a Fossur-Mer (industrial e cargas), conforme Figura 2. É gerido pela autoridade portuária Grande Porto Marítimo de Marselha-Fos GPMM (Grand Port Maritime de Marseille-Fos) sob a tutela do estado francês, a qual, por sua vez, é exercida pela Direção Geral de Infraestrutura, Transporte e Mar, vinculada ao Ministério da Ecologia, do Desenvolvimento Sustentável e Energia. O porto de Marselha-Fos é hoje o segundo maior do Mediterrâneo em movimentação (ANDRÉ, 2014). Entretanto, vale ressaltar que Marselha-Fos é um porto de hinterlândia voltado para a demanda doméstica, diferentemente do porto espanhol de Algeciras, localizado na Baía de Gibraltar, que é um porto de transbordo semelhante ao porto marroquino de Tanger Med Port Authority (TMPA). 


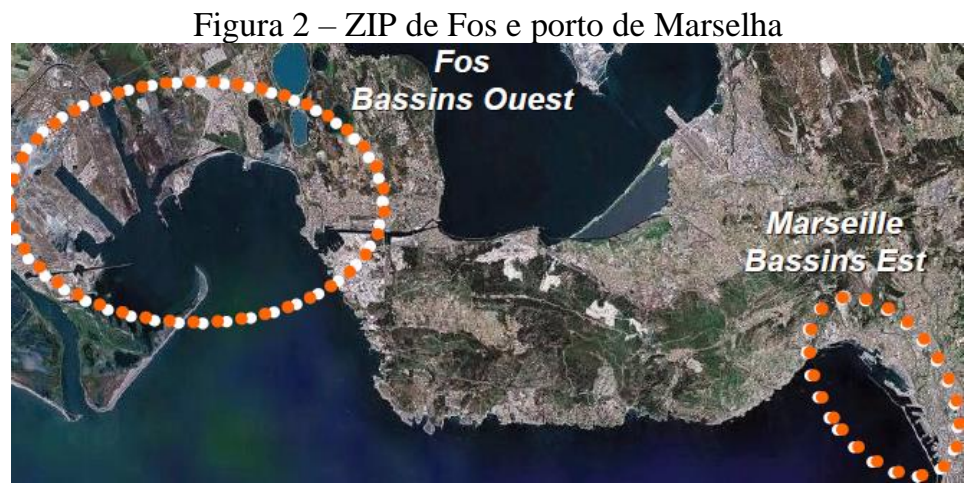

Fonte: Grande Porto Marítimo de Marselha-Fos (GPMM).

De qualquer modo, o porto tem alterado sua postura mercadológica devido à concorrência, investindo na logística de distribuição (zonas de Fos Distriport e La Feuillane, com 3 milhões de $\mathrm{m}^{2}$ ) e no transporte de contêineres (conforme Tabela 1), o que se consubstancia nas diretrizes comerciais adotadas pela atual presidente Christine Cabau-Woehrel (ex-diretora do armador CMA-CGM). Nesse sentido, a preocupação com a eficiência desencadeou a implantação de um software (Cargo Community System AP+) que congrega os atores envolvidos na passagem portuária (públicos e privados). Segundo o diretor responsável Loïc Bezombes, a tecnologia possibilita fluidez, não deixando o tempo médio de desembaraço aduaneiro passar de cinco minutos. Isso permite que $93 \%$ dos navios acessem o cais sem necessidade de espera.

\begin{tabular}{|c|r|r|}
\multicolumn{3}{|c}{ Tabela 1 - Tráfego do GPMM } \\
\hline Ano & $\begin{array}{c}\text { Carga movimentada } \\
\text { (milhões de toneladas) }\end{array}$ & $\begin{array}{c}\text { Contêineres } \\
\text { (TEU) }\end{array}$ \\
\hline 2010 & 86 & 953.435 \\
\hline 2011 & 88,07 & 944.047 \\
\hline 2012 & 85,79 & 1.061 .193 \\
\hline 2013 & 80,04 & 1.097 .740 \\
\hline 2014 & 78,52 & 1.179 .910 \\
\hline 2015 & 81,73 & 1.223 .071 \\
\hline \multicolumn{3}{|r|}{ Fonte: GPMM } \\
\hline
\end{tabular}

A ZIP de Fos tem cerca de 12 mil hectares (CATY; RICHARD, 2003). Contando com um calado de até 18 metros, o complexo portuário e industrial possui refinarias, siderúrgicas, instalações de armazenamento, terminais de petróleo, de minério, petroquímico e de contêineres, tancagem para armazenamento de petróleo bruto e produtos refinados, produtos químicos e armazenamento de gás natural 
em subsolo (CATY; RICHARD, 2003; MERK; COMTOIS, 2012). Sua multimodalidade oferece conexões fluviais, oleodutos, ferrovias e rodovias. O porto é a principal entrada marítima para hidrocarbonetos na França, representando cerca de $70 \%$ do volume movimentado.

\subsubsection{Modelo de governança do GPMM}

Na França, a governança portuária é tradicionalmente controlada pelo governo central. A criação dos portos autônomos, entre 1923 e 1965, objetivou reduzir a influência da economia local, em especial das câmaras de comércio (chambres de commerce et d'industrie - CCI). $\mathrm{O}$ forte papel do estado tem persistido nos sete maiores portos, incluindo Marselha-Fos, com o estatuto de grandes portos marítimos (GPM), criado pela reforma portuária de 2008 e implementado em 2011 (DEBRIE; LAVAUD-LETILLEUL，2010). Em tais portos, o estado continua a ser $\mathrm{o}$ ator dominante aplicando a lógica das infraestruturas de interesse nacional.

Dessa forma, em 2012, o porto de Marselha-Fos alterou seu modelo de exploração, passando de service port para landlord público, possibilitado pela reforma portuária francesa. Com a nova configuração, uma área de 100 hectares e 1.600 metros de cais passou a ser explorada pelas empresas: Fos Holding (MSC/Seayard - operador Seayard) e Port Synergy (CMA-CGM/DPW - operador Eurofos). Como landlord público, a autoridade portuária GPMM é também responsável pela gestão territorial, incluindo as políticas de atração industrial.

A governança portuária do GPMM se alicerça em três instâncias: Conselho de Administração, Conselho de Fiscalização e Conselho de Desenvolvimento. O Conselho de Administração tem como atribuições: desenvolver o projeto estratégico (posicionamento estratégico e política de desenvolvimento do GPMM); definir as atividades a serem exploradas e os métodos a serem operacionalizados; e elaborar a política de planejamento e desenvolvimento sustentável do porto e das conexões intermodais. Ao Conselho Fiscal cabe adotar o projeto estratégico apresentado pelo Conselho de Administração, votar o orçamento anual e aprovar os investimentos mais importantes. E o Conselho de Desenvolvimento é a instância consultiva sobre o projeto estratégico e o relatório anual de execução antes da deliberação do Conselho Fiscal e política de taxas portuárias. Os membros são eleitos ou designados para um mandato de 5 anos (período 2014-2018). A composição das três instâncias de governança é apresentada no Quadro 3. 
Quadro 3 - Governança portuária do GPMM

\begin{tabular}{|l|l|}
\hline \multicolumn{1}{|c|}{ Instâncias } & \multicolumn{1}{c|}{ Membros } \\
\hline Conselho de Administração & -1 : presidente, nomeado por decreto presidencial \\
& -3 : nomeados pelo presidente do Conselho \\
\hline Conselho Fiscal & -5 : nomeados pelo estado francês \\
& -3 : funcionários do GPMM \\
& -4 : autoridades locais (municipais) \\
& -5 : personalidades qualificadas \\
\hline Conselho de Desenvolvimento & -12 : empresas que fazem uso do porto \\
& -4 : representantes de trabalhadores que exercem atividades no \\
& porto \\
& -12 : autoridades locais (municipais) \\
& -12 : personalidades qualificados \\
\hline
\end{tabular}

Fonte: GPMM.

\subsection{Complexo Industrial e Portuário do Pecém - CIPP}

O Governo Federal do Brasil, em parceria com o governo do estado do Ceará, através da Secretaria de Infrastrutura do Estado (SEINFRA), inaugurou oficialmente, em março de 2002, o Terminal Portuário do Pecém. A sua implantação destinava-se a facilitar o funcionamento das atividades portuárias e industriais integradas. Dada a extensão territorial da ZIP do Pecém, sua área abrange dois municípios: Caucaia e São Gonçalo do Amarante, ambos situados na região metropolitana de Fortaleza. O Complexo Industrial e Portuário do Pecém (CIPP), que conta com uma zona de processamento de exportação (ZPE), está situado a cerca de $50 \mathrm{~km}$ da capital, Fotaleza, e sua extensão é de 13.337 hectares. Essa área é inserida em uma área maior de $335 \mathrm{~km}^{2}$.
O porto do Pecém é gerido e explorado pela autoridade portuária Companhia de Integração Portuária do Ceará (Cearáportos), constituída sob a forma de sociedade de economia mista, tendo como único acionista o governo do estado do Ceará, o que nos permite enquadrá-lo como um porto industrial regional. O terminal portuário do Pecém não é público, daí não necessitar de conselho de autoridade portuária (CAP), de órgão gestor de mão de obra (OGMO) ou de operador portuário e de regulamento de exploração e tarifas. Tal fato imprime ao porto eficiência no tocante aos custos operacionais e garante aos usuários a continuidade das operações. Na Tabela 2, apresentamos a movimentação do porto do Pecém nos últimos anos. 
Tabela 2 - Tráfego do porto do Pecém

\begin{tabular}{|r|r|r|}
\hline Ano & $\begin{array}{c}\text { Carga movimentada } \\
\text { (milhões ton) }\end{array}$ & $\begin{array}{c}\text { Contêineres } \\
\text { (TEU) }\end{array}$ \\
\hline 2010 & 3,53 & 159.200 \\
\hline 2011 & 3,77 & 192.909 \\
\hline 2012 & 4,39 & 153.141 \\
\hline 2013 & 6,33 & 149.979 \\
\hline 2014 & 8,27 & 195.350 \\
\hline 2015 & 7,01 & 180.393 \\
\hline
\end{tabular}

Fonte: Cearáportos.

O porto do Pecém nasce dentro de uma concepção mercadológica ajustada às tendências mundiais do setor. A autoridade portuária Cearáportos atua no modelo de porto quase-público (tool port), também conhecido como terminal de uso privativo misto, possibilitado pela Lei de Modernização dos Portos. As áreas de uso restrito são geridas como se fossem de uso comum, uma vez que não há terminais privativos no porto do Pecém. Dessa forma, os operadores logísticos que atuam no porto do Pecém compartilham todas as áreas. No entanto, a responsabilidade da autoridade portuária restringe-se à área do porto que engloba sua superestrutura, ou seja, seu core services consistem em logística de transporte e atividades afins, diferentemente do que se verifica em Marselha e em Roterdã, onde as autoridades portuárias também gerenciam as áreas industriais.

\subsubsection{Modelo de governança do CIPP}

As primeiras iniciativas de formalizar um projeto de governança organizada para a ZIP do Pecém datam de seis anos após a inauguração. Foi o Decreto $\mathrm{N}^{\mathrm{o}} 29.228$, de 13 de março de 2008, que instituiu o grupo de trabalho interdisciplinar (GTI), cujas atribuições incluíam a questão das áreas a serem desapropriadas e a elaboração do termo de referência do plano diretor do CIPP. Em 2010, em resposta ao Ministério Público, o governo do estado criou o Grupo de Monitoramento de Ações Interinstitucionais e Setoriais (GMAIS), com o objetivo de fortalecer o diálogo com todos os atores que compõem o entorno do CIPP e minimizar os impactos socioambientais gerados pela ZIP. Entretanto, a iniciativa sofreu descontinuidade.

Foi com a Lei 15.083, de 21 de dezembro de 2011, que se instituiu o modelo de gestão do CIPP, criando a Unidade Gestora (executivo) e o Conselho 
Gestor (deliberativo) do CIPP e das áreas do entorno. Ficaram a cargo dessas instâncias: a gestão do CIPP, o planejamento, a instalação de novas indústrias, a ampliação de indústrias já estabelecidas e a criação de empresas, conforme o plano diretor do CIPP. O Conselho Gestor do CIPP e das áreas do entorno estaria vinculado ao Gabinete do Governador e seria composto de 27 membros, dos quais 24 estariam vinculados ao governo do estado do Ceará, 2 membros das prefeituras em que o CIPP está localizado e 1 membro da Assembleia Legislativa do Estado do Ceará.

A Lei 15.248, de 17 de dezembro de 2012, alterou a composição do Conselho, ampliando para 33 representações, abrindo espaço para a participação da sociedade civil. O Decreto 31.509 de 9 de julho de 2014 alterou novamente a composição dos membros do Conselho e nomeou para presidir o Conselho Gestor o presidente do Conselho Estadual de Desenvolvimento Econômico (CEDE). Com a extinção do CEDE, o Conselho passaria a ser presidido pelo Secretário de Desenvolvimento Econômico (SDE). Ficou sob responsabilidade do Conselho Gestor: referendar o Plano Básico de Ação e os planos operacionais anuais, apresentados pela Unidade Gestora; avaliar a situação do CIPP; e opinar sobre a instalação de empreendimentos industriais e empresas no CIPP.

Por sua vez, a Unidade Gestora do CIPP teria como atribuições: planejar, executar e avaliar as ações para garantir o pleno funcionamento do CIPP; articular-se com órgãos da administração federal, instâncias municipais e entes privados instalados no CIPP; e propor programas a serem desenvolvidos nas áreas de influência do CIPP, com foco no desenvolvimento regional sustentável. A Unidade Gestora teria a seguinte estrutura básica: presidência, diretoria de planejamento e gestão, diretoria de sustentabilidade socioambiental, diretoria de infraestrutura e ouvidoria. Todos os cargos preenchidos por livre nomeação pelo governador do estado, conforme artigo $8^{\circ}$, inciso $1^{\circ}$, da lei que normatiza seu funcionamento.

No entanto, segundo o relatório Pacto pelo Pecém (CAECE, 2013), ratificado pela pesquisadora Rossana Garjulli (coordenadora do relatório), o Conselho e a Unidade Gestora ainda não funcionam conforme previsto em lei. $\mathrm{Na}$ prática, o CIPP é gerido pela SEINFRA, o que se justifica devido às carências infraestruturais do projeto, com o apoio de outros órgãos de estado implicados em atividades específicas, a exemplo da Procuradoria Geral do Estado (PGE) e do Instituto de Desenvolvimento Agrário do 
Ceará (Idace), ambos empenhados na regularização fundiária e desapropriações. Entretanto, a tomada de decisões na ZIP continua a ser prerrogativa exclusiva do Governador do Estado.

O modelo de Conselho Gestor e Unidade Gestora foi aperfeiçoado com base no relatório Pacto pelo Pecém e na consultoria da empresa Dialog, contratada pela Companhia Siderúrgica do Pecém
(CSP). De acordo com Helena Grundig, gerente de projetos da consultoria, o modelo proposto sugeria, dentre outras instâncias, a criação de fóruns regionais destinados a discussões mais amplas e gerais (com fim propositivo), conselhos regionais (deliberativo), um consórcio público para gerir o CIPP (executivo) e um observatório (monitoramento), conforme Figura 3.

Figura 3 - Organograma propositivo de governança do CIPP

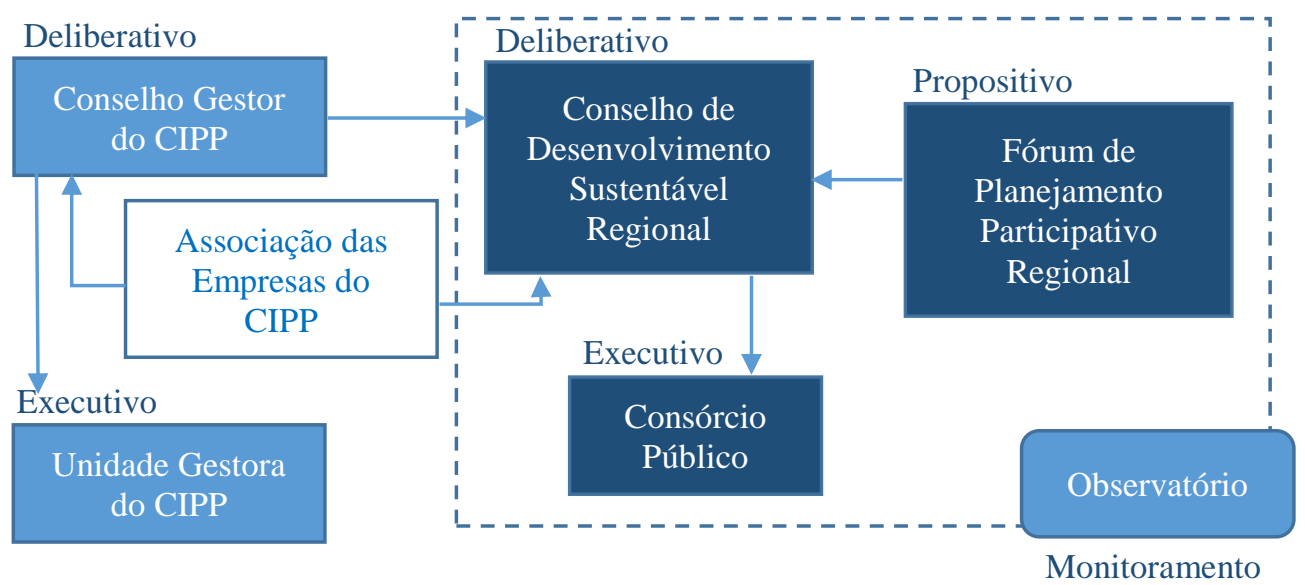

Fonte: Dialog/ONU-Habitat.

Contudo, o modelo de governança proposto não foi acatado pelo Governo do Ceará, pois o Estado estava aguardando as proposições de outra consultoria, contratada junto à autoridade portuária de Roterdã. Em caráter preliminar, ou seja, sem publicação em um relatório final, a consultoria do porto Roterdã propôs para a gestão do CIPP as seguintes medidas (URIBE, 2016):

- gerar coesão institucional para que o CIPP aja de maneira integrada;
- aumentar sinergias entre porto e indústria, dada sua dependência mútua;

- planejar de forma integrada o CIPP, englobando um plano comercial e espacial;

- aumentar a capacidade de investimento com nova modelagem para atração de investimentos.

Segundo o governador do Estado, o porto do Pecém deverá se preparar para abertura de capital, cujo modelo ainda não 
foi definido. O modelo de concessão, que deverá incluir a gestão de todo o CIPP, poderá se dar na forma de uma parceria público-privada (PPP). O próprio porto de Roterdã tem sinalizado com interesse na parceria. Em 22 de março de 2017, o Governador do Estado do Ceará e o CEO da autoridade portuária de Roterdã assinaram um memorando de entendimento (memorandum of understanding - MoU) formalizando o desejo de parceira.

\section{METODOLOGIA}

Este estudo possui abordagem qualitativa, de caráter exploratório e descritivo. Dessa maneira, utiliza-se do método dedutivo-hipotético, em relação recíproca com os estudos de caso, ou seja, baseia o conhecimento do fenômeno observado em representações da realidade e na caracterização de casos distintos.

Os dados foram coletados em pesquisas de campo em duas ZIPs, localizadas uma na França e a outra no Brasil. Essa fase da pesquisa é compreendida como um momento que favorece a emersão dos conhecimentos práticos e teóricos (DAVID, 2000). Em seguida, ao analisarmos os dados coletados em campo, identificamos um volume considerável de semelhanças na forma gestionária das duas ZIPs, sobretudo, no que se refere às suas fragilidades. $\mathrm{O}$ porto de Roterdã foi utilizado como modelo de parametrização para as duas ZIPs estudadas.

Com efeito, os modelos portuários dos dois países são caracterizados e comparados, conforme sua organização, a partir de fontes primárias (entrevistas semiestruturadas e observaçãoparticipação) e secundárias (fontes bibliográficas) (YIN, 1989; THIERTART et al., 2014). De modo a fazer uma boa descrição das duas ZIPs, foram realizadas, com stakeholders de cada uma, 26 entrevistas individuais semiestruturadas. $\mathrm{Na}$ ZIP de Fos, realizamos 12 entrevistas; na ZIP do Pecém, 13 entrevistas. Além disso, entrevistamos uma funcionária da autoridade portuária de Roterdã.

As ZIPs foram selecionadas devido às suas relevantes distinções e semelhanças, permitindo comparações entre os modelos. A região Provence-Alpes-Côte d'Azur, no litoral Mediterrâneo, onde está inserida a ZIP de Fos, está para o restante da França assim como o Nordeste está para o restante do Brasil, guardadas as devidas proporções, pois trata-se de uma região com menores índices de desenvolvimento econômico e social. Outro ponto comum aos dois aparelhos é o espaço geográfico onde foram inseridos: ambos em vilas de pescadores 
sem nenhuma cultura portuária e industrial anterior.

\section{ANÁLISE DOS RESULTADOS}

$\mathrm{Na}$ ZIP de Marselha-Fos, as instâncias de governo locais estão envolvidas em algumas esferas de gestão, todavia sua influência se limita à tomada de decisão. Como verificamos, elas são representadas no Conselho Fiscal com 4 dos 17 lugares, e as demais vagas acabam ocupadas pelo estado central. As autoridades locais também integram o Conselho de Desenvolvimento, mas este possui apenas uma função consultiva $e$, novamente, elas estão representadas em proporção inferior (MERK; COMTOIS, 2012). Além de uma baixa representatividade das instituições locais na gestão do porto, o estado é o único acionista da GPMM, fato que pode explicar o distanciamento do GPMM das questões de desenvolvimento regional e sua inclinação a questões nacionais como o comércio de hidrocarbonetos.

Com a criação da metrópole AixMarselha Provença, poderá surgir uma forma de gestão regionalizada do GPMM. O governo metropolitano deverá estar representado nas esferas da gestão portuária (Conselho Fiscal e Conselho de Desenvolvimento) com maior poder decisório. Isso pode assumir a forma de um sistema de gestão partilhada entre o novo governo metropolitano e o estado, assemelhando-se ao modelo de Roterdã.

Em entrevista com o prefeito de Fossur-Mer René Raimondi e os secretários de desenvolvimento econômico da região, Hélène Fossati (Agglomération du Pays de Martigues) e Emmanuel Thomas (Intercomunalité San Ouest Provence), fica evidente a insatisfação com a atuação do GPMM no que diz respeito à política industrial. Um dos pontos levantados pelos entrevistados versava sobre os critérios considerados pelo GPMM para atrair projetos industriais, em que a ponderação dada à geração de tráfego pelos projetos industriais são, sobremaneira, superiores a outros fatores como, por exemplo, a questão de desenvolvimento econômico da região. Tal posicionamento também foi revelado em entrevista à executiva do GPMM Geraldine Planque, quando ressaltou a prioridade dispensada aos setores de logística de transporte, armazenamento e distribuição, em detrimento do setor industrial. A literatura destaca que os rendimentos obtidos pela ZIP e pela região do entorno são maximizados quando a autoridade portuária consegue, em seu business model, tratar de forma integrada e coesa as atividades logísticas e industriais. 
De acordo com Duna Uribe, da autoridade portuária de Roterdã, o modelo de gestão de uma ZIP não pode dissociar a área portuária propriamente dita da industrial, como se verifica no modelo de Roterdã. As duas áreas devem estar contidas em um projeto de gestão com vistas ao desenvolvimento conjunto, imperativamente submetido, por sua vez, ao desenvolvimento econômico e sustentável da região. Entendimento esse não verificado nas ZIPs estudadas. Na do Pecém, o descompasso comercial e gestionário toma proporções maiores pelo fato de a autoridade portuária Cearáportos restringirse às atividades portuárias stricto sensu. $\mathrm{Na}$ área da ZIP, é possível verificar um emaranhado de empresas públicas e secretarias de estados intervindo direta e indiretamente na gestão, ademais sem as diretrizes estratégicas de uma estrutura formal de governança.

Um ponto comum entre as duas ZIPs estudadas é a resposta da iniciativa privada a descompassos nos modelos de governança. Na ZIP de Fos, identificamos o projeto plug \& play, de Plataforma Industrial e de Inovação Caban Tonkin PIICTO. Desde o final de 2013, empresários da ZIP estão mobilizados nessa iniciativa com o objetivo de criar sinergia, particularmente, em matéria de energia, mas também de produtos e serviços, em uma abordagem de economia circular. De acordo com o diretor da empresa química Ken One e um dos idealizadores do projeto, Patrick Grimald, dois fatores motivaram a classe empresarial: a crise econômica e a deficiência do GPMM no que se refere a pilotar projetos e políticas para o setor industrial.

À espera de um modelo de governança, empresários criaram, em 2015, a Associação das Empresas do CIPP (AECIPP), com o objetivo de fortalecer e desenvolver a atividade empresarial na ZIP. De acordo com o primeiro presidente da AECIPP e presidente da termelétrica ENEVA, Fernando Moura, a entidade representativa foi instituída ensejando construir melhor interlocução com o governo do estado. Assim, uma das suas principais demandas é implantar o modelo de governança para o CIPP. A Associação também trabalha princípios de cooperação e mutualização entre as empresas do CIPP.

O modelo de gestão do porto de Roterdã, fruto de aperfeiçoamentos $\mathrm{e}$ constantes adaptações aos ditames do dinâmico setor logístico de transportes, traz consigo um desenho institucional amadurecido que pode servir como benchmarking para as demais instituições. Esse modelo pode ser incorporado, por exemplo, no tratamento despendido ao setor industrial e logístico de forma indistinta, 
consubstanciado na criação de diretorias para cada setor vinculadas diretamente ao CEO. Essa é uma estrutura organizacional que poderia produzir efeitos positivos para a autoridade GPMM. Todavia, o modelo (ainda em desenvolvimento) do CIPP poderia aperfeiçoar-se com a ampliação do papel da autoridade Cearáportos, a qual passaria a gerir também a ZIP. Por último, o modelo holandês pode oferecer a ambas as ZIPs as exitosas práticas de concertação, como forma de criar capital social, sinergia e proximidades.

\section{CONCLUSÃO}

Fica evidente que, em matéria de gestão portuária, a tendência mundial é acompanhar as prescrições de instituições mundiais como a OCDE e o Banco Mundial, que estimulam os governantes a adotarem políticas liberalizantes para o setor portuário, com o estímulo crescente da iniciativa privada. Assim, as duas ZIPs estudadas têm empreendido esforços nessa direção: atraírem investimentos da iniciativa privada e, consequentemente, tornarem-se mais eficientes em termos operacionais.

Por outro lado, infraestruturas portuárias devem possuir gestão regionalizada, sobretudo, em se tratando de porto industrial. Essa constatação corrobora a assertiva de que cidades não implicadas na gestão de seus portos podem tornar-se menos dispostas a criar condições favoráveis ao desenvolvimento portuário (conexões logísticas que ampliem sua área de influência), gerando uma interface cidade-porto conflituosa.

A autoridade portuária responsável pela governança territorial da ZIP deverá exercer uma coordenação centralizada capaz de congregar os atores em torno de um objetivo comum, assim como atuar como agente catalisador do desenvolvimento industrial e logístico. Para isso, necessita de maior representatividade perante órgãos públicos e privados. Dessa maneira, arregimentar a participação na gestão da infraestrutura industrial-portuária dos stakeholders envolvidos na operação passa a ser uma meta capaz de criar aproximações institucionais e organizacionais. Isso permitirá que se expurguem os gargalos a impedir o bom funcionamento do ativo logístico e que se crie maior dinamicidade para os processos.

Ademais, cabe a uma ZIP a missão de proporcionar o desenvolvimento econômico e social da região e do seu entorno de forma inclusiva e participativa, criando um diálogo cidade-portoindústrias-sociedade e tendo como resultado a criação de sinergias. Para tanto, a ferramenta de governança que se coloca é 
a comunicação empreendida por inúmeros

canais, a serem alimentados e animados

constantemente pela autoridade portuária. 


\section{REFERÊNCIAS}

ANDRE, F. Marseille n'est plus le premier port de Méditerranée. L’antenne, 2014. Disponível em: $<w w w . l a n t e n n e . c o m / M a r s e i l l e-n-e s t-p l u s-l e-p r e m i e r-p o r t-d e-$ Mediterranee_a17047.html>. Acesso em: 26 mar. 2017.

CAECE. Cenário Atual do Complexo Industrial e Portuário do Pecém - Pacto pelo Pecém. Instituto de Estudos e Pesquisas para o Desenvolvimento do Estado do Ceará - INESP, Conselho de Altos Estudos e Assuntos Estratégicos da Assembleia Legislativa do Estado do Ceará - CAECE, Fortaleza / Ceará, 2013.

CATOIRE, S. et al. La mise en ouvre des projets portuaires pour y developper durablement les activites logistiques et industrielles. Ministère de l'écologie, du développement durable et de l'énergie. Governo Francês, 2013.

CATY, R.; RICHARD, E. Le transport maritime : le Port Autonome de Marseille. Edition Jeanne Leffitte, Marseille, 2003.

CEARÁ. Decreto $\mathrm{N}^{\mathrm{o}}$ 29.228, de 13 de março de 2008. Disponível em: <www.jusbrasil.com.br/diarios/5302558/pg-33-caderno-1-diario-oficial-do-estado-do-cearadoece-de-14-03-2008>. Acesso em: 30 set. 2016.

Decreto $\mathrm{n}^{\mathrm{o}}$ 31.509, de 09 de julho de 2014. Disponível em: <www.jusbrasil.com.br/diarios/72905083/doece-caderno-1-11-07-2014-pg-18>. Acesso em: 12 nov. 2016.

. Grupo de Monitoramento de Ações Interinstitucionais e Setoriais (GMAIS). Disponível em: <www.semace.ce.gov.br/2010/12/cipp-ganhara-mosaico-criado-pelasemace/> e <www.ceara.gov.br/sala-de-imprensa/noticias/1329-governo-apresenta-plano-deacoes-para-o-cipp>. Acesso em: 22 set. 2016.

Lei $\mathrm{n}^{\circ} 15.083,21$ de dezembro de 2011. Diário Oficial do Estado, série 3, Ano III, $\mathrm{n}^{\circ}$ 248, Fortaleza, 29 de dezembro de 2011,

<www.al.ce.gov.br/legislativo/legislacao5/leis2012/15248.htm>. Acesso em: 20 nov. 2016.

CNI. Problemas históricos de infraestrutura do país podem ser transformados em oportunidade de investimentos. 2016. Disponível em : <www.portaldaindustria.com.br/agenciacni/noticias/2016/06/problemas-historicos-de- 
infraestrutura-do-pais-podem-ser-transformados-em-oportunidade-de-investimentos-1/> . Acesso em: 15 jan. 2017.

COUTINHO, P. et al. Modelos da estrutura do setor portuário no mundo e no Brasil, referencial teórico e metodologias para estudo da concorrência interportos e intraportos no Brasil. Centro de Excelência em Regulação de Mercados - CERME, Relatório 1, Universidade de Brasília, 2013.

BRITTO, P. A. et al. Promoção da concorrência no setor portuário: uma análise a partir dos modelos mundiais e aplicação ao caso brasileiro. Rev. Adm. Pública, p. 47-71, 2015.

DAVID, A. Logique, épistémologie et méthodologie en Sciences de gestion : trois hypothèses revisitées. In: David A. ; Hatchuel A. ; Laufer R. Les nouvelles fondations des sciences de gestion. Paris: Vuibert, 2000.

DEBRIE, J.; LAVAUD-LETILLEUL, V., La Décentralisation portuaire : réformes, acteurs, territoires. Paris: L'Harmattan, 2010.

FALCÃO, V. A.; CORREIA A. R. Eficiência portuária: análise das principais metodologias para o caso dos portos brasileiros. Journal of Transport Literature, v. 6, n. 4, p.133-146, 2012.

GUILLAUME, J. Le système productif d'énergie de la Basse-Loire, quelle durabilité ? Géoconfluences, 2014. IGARUN, Université de Nantes, 2014. Disponível em: <geoconfluences.ens-lyon.fr/informations-scientifiques/dossiers-regionaux/la-france-desterritoires-en-mutation/articles-scientifiques/le-systeme-productif-d2019energie-de-la-basseloire-quelle-durabilite>. Acesso em: 24 nov. 2017.

GUEGUEN-HALLOUËT, G. Rôle croissant du secteur privé dans l'activité et la gestion des ports. Les grands ports mondiaux, n. 70, La Documentation française, 2014.

MERK, O.; COMTOIS, C. Compétitivité des villes portuaires: Le cas de Marseille-Fos. OECD Regional Development Working Papers, 2012/11, OECD Publishing, 2012.

MONIÉ, F.; VASCONCELOS F. N. Evolução das relações entre cidades e portos: entre lógicas homogeneizantes e dinâmicas de diferenciação. Revista franco-brasileira de geografia Cofins, n. 15, 2012.

NOTTEBOOM, T. Consolidation and contestability in the European container handling industry. Maritime Policy and Management, v. 29, n. 3, p. 257-269, 2002. 
PERROUX, F. L’Économie du XXe siècle. 3e édition, 1991.

PICCTO. Plataforma Industrial e de Inovação Caban Tonkin. Disponível em: <mediterranee.uic.fr/content/download/528464/5880574/file/140930\%20-

$\% 20$ Presentation $\% 20$ PIICTO $\% 20-\% 20 \mathrm{CSF} \% 20 \mathrm{Chimie} \% 20 \% 20 \mathrm{Materiaux}$.pdf $>$. Acesso em: 12 nov. 2016.

PORT OF ROTTERDAM. Organisation: Port authority, developer, manager and operator. Disponível em: <www.portofrotterdam.com/en/port-authority/organisation>. Acesso em: 24 jan. 2017.

Port Information Guide, Harbour Master Port of Rotterdam, 2016. Disponível em: 〈www.portofrotterdam.com/en/shipping/sea-shipping>. Acesso em: 12 fev. 2017.

Project: new land in the sea [Maasvlakte 2]. Disponível em:

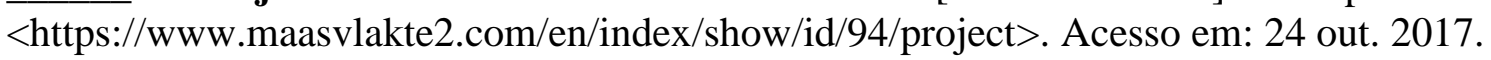

THIERTART, R.-A. et al. Méthodes de Recherche en Management. Paris: Dunod, 2014.

TOURRET, P. Ports et industries en France. Note de synthèse, n. 137, Institut Supérieur d'Economie Maritime, ISEMAR, 2011.

URIBE, D. G. Visão do Porto de Roterdã para o futuro do Complexo Industrial e Portuário do Pecém. Port of Rotterdam, Expolog - Feira Nacional de Logística, Fortaleza, 2016.

YIN, R. K. Case study research: Design and methods. Beverly Hills: Sage Publishing, 1989.

WANG J. J.; OLIVIER D. La gouvernance des ports et la relation ville-port en Chine. Les Cahiers Scientifiques du Transport, n. 44, p. 25-54, 2003.

WORLD BANK. Port reform toolkit. Washington: World Bank Institute, 2003.

, Reforming infrastructure: privatization, regulation and competition. World Bank Policy Research Report. Washington, DC: The World Bank, 2004. 